\title{
Re-emergence of animal rabies in northern Greece and subsequent human exposure, October 2012 - March 2013
}

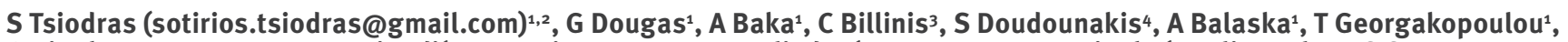

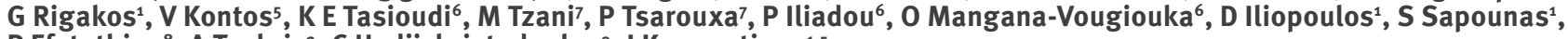

P Efstathiou $^{8}$, A Tsakris ${ }^{2}$, C Hadjichristodoulou', J Kremastinou ${ }^{1,5}$

1. Hellenic Center for Disease Control and Prevention (KEELPNO), Ministry of Health, Athens, Greece

2. National and Kapodistrian University of Athens Medical School, Athens, Greece

3. School of Veterinary Medicine, University of Thessaly, Karditsa, Greece

4. Directorate General of Veterinary Services / Animal Health Directorate, Ministry of Rural Development and Food, Athens, Greece

5. National School of Public Health, Athens, Greece

6. Virology Department, Institute of Infectious and Parasitic Diseases, Athens Center of Veterinary Institutes, Ministry of Rural Development and Food, Athens, Greece

7. Department of Zoonoses, Animal Health Directorate, General Veterinary Directorate, Ministry of Rural Development and Food, Athens, Greece

8. National Health Operations Center of the Ministry of Health (EKEPY), Athens, Greece

9. Department of Hygiene and Epidemiology, University of Thessaly, School of Medicine, Larissa, Greece

Citation style for this article:

Tsiodras S, Dougas G, Baka A, Billinis C, Doudounakis S, Balaska A, Georgakopoulou T, Rigakos G, Kontos V, Efstathiou P, Tsakris A, Hadjichristodoulou C, Kremastinou J. Re-emergence of animal rabies in northern Greece and subsequent human exposure, October $2012-$ March 2013 . Euro Surveill.

2013;18(18):pii=20474. Available online: http://www.eurosurveillance.org/ViewArticle.aspx?Articleld=20474

Article submitted on 22 April 2013 / published on 2 May 2013

Greece has been rabies-free since 1987 with no human cases since 1970. During 2012 to 2013 , rabies has reemerged in wild and domestic animals in northern Greece. By end March 2013, rabies was diagnosed in 17 animals including 14 red foxes, two shepherd dogs and one cat; 104 subsequent human exposures required post-exposure prophylaxis according to the World Health Organization criteria. Human exposures occurred within $50 \mathrm{~km}$ radius of a confirmed rabies case in a wild or domestic animal, and most frequently stray dogs were involved.

\section{Introduction}

The last animal rabies case in Greece, dates back to 1987 while the last human case was reported in 1970 [1]. Here we describe the re-emergence of rabies in both wild and domestic animals during October 2012 to end March 2013 in northern and central Greece that was associated with human exposure. We discuss significant public health implications of the situation.

\section{Rabid fox}

On 15 October 15 2012, a red fox (Vulpes vulpes) exhibited aggressive behavior during daytime, threatening inhabitants of a west Macedonian village in the area of Kozani. The animal was destroyed and transported to the National Reference Laboratory (NRL) for Animal Rabies at the Centre of Athens Veterinary Institutions Virus Department, of the Ministry of Rural Development and Food as part of a wild animal surveillance program for rabies organised and implemented by the Ministry of Rural Development since April 2012 because of documented presence of lyssavirus in neighboring Balkan countries. Four days later on 19 October, the brain samples tested positive for lyssavirus by fluorescence antibody test (FAT) and molecular techniques i.e. real-time RT-PCR and RT-PCR followed by sequencing.

\section{Rabid shepherd dog and exposure of humans and domestic animals}

On 10 November 2012, in west Macedonia, near the Greek-Albanian border in the area of leropigi, Kastoria, a shepherd dog, belonging to a herdsman, bit the thigh of a passing-by hunter unprovoked. Two days later, on 12 November, the dog developed an aggressive behaviour attacking other dogs and sheep of the herd. It was consequently destroyed and brain tissue samples investigated at the NRL in Athens were positive for lyssavirus both by FAT and molecular techniques on 16 November.

Tracing of exposed humans and animals and first control measures

An epidemiological investigation was initiated on 16 November by the Emergency Response Center of the Hellenic Centre for Diseases Control and Prevention (KEELPNO), Athens, in order to identify all individuals who had had contact with the dog and possible exposure to the lyssa virus. Seven people possibly exposed were interviewed. Besides the hunter and the shepherd, three relatives of the latter reported close exposure according to the World Health Organization exposure category III [2] i.e. dog bite and/or mucous membrane exposure to the rabid dog. All five including 
Geographical location and type of animals with rabies identified through the animal surveillance program for rabies, Greece October 2012 to end March $2013(\mathrm{n}=17)$

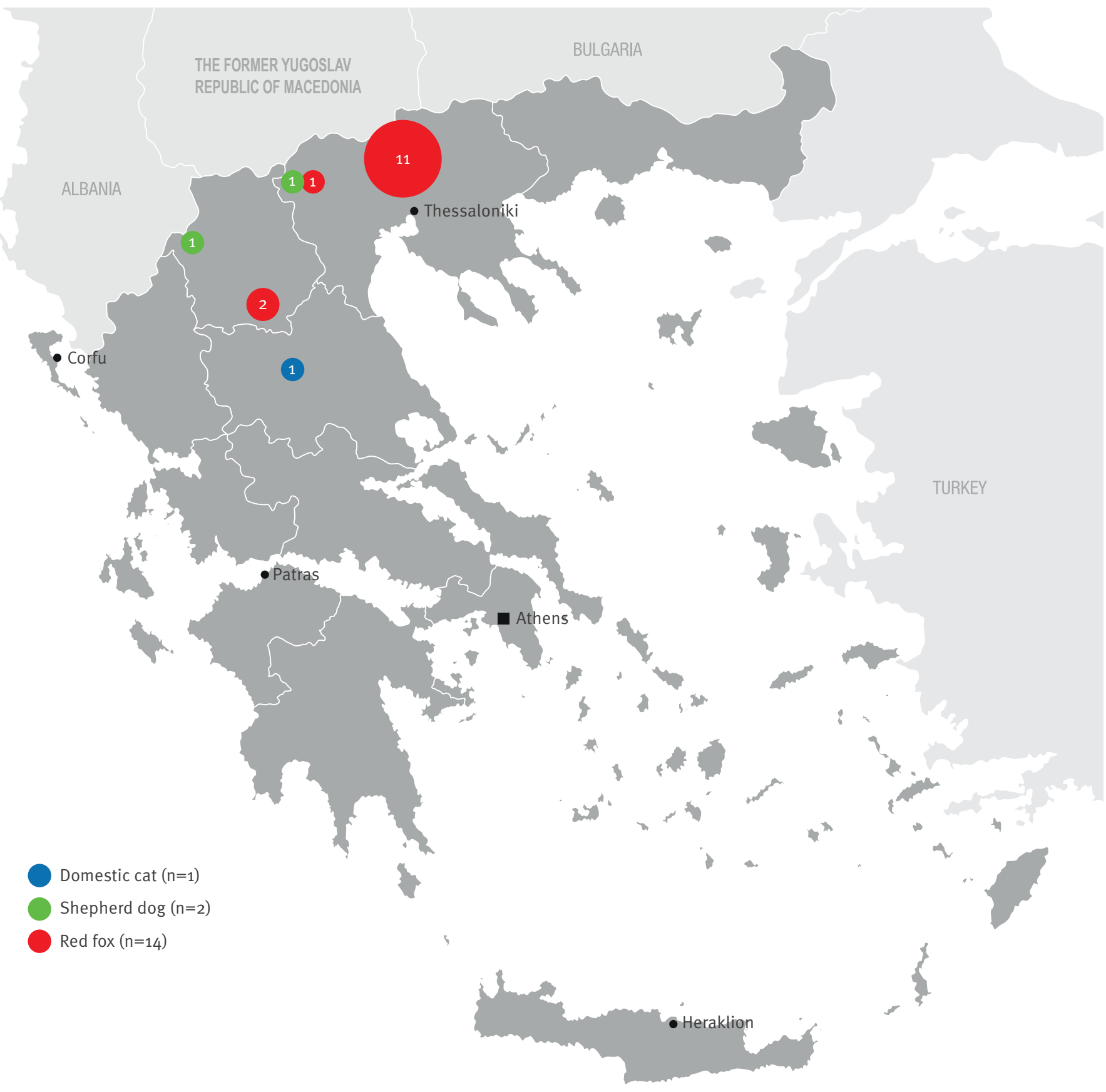

the veterinarian that had sampled the animal received human rabies immunoglobulin along with rabies immunisation series. None of the exposed individuals has developed any symptoms of human rabies so far. Two further possible contacts did not fulfill the WHO criteria for post-exposure prophylaxis.

Testing of brain samples from one exposed dog gave negative results. Hunting was prohibited in the affected area within a radius of $5 \mathrm{~km}$ for 15 days and all shepherd dogs (approximately 800) were vaccinated against rabies during the next 15 days.

\section{Results from regular rabies surveillance November to March 2013}

In addition to the two animal cases described, and through the enhanced surveillance instituted by the veterinarian authorities, since November 2012 until end March 2013 we have identified additional 13 red foxes, one shepherd dog (20 December 2012) and one domestic cat (28 February 2013) with laboratory confirmed rabies (Figure). No dead wild or domestic animals were found except for the aforementioned domestic cat that was free to circulate outside the owner's house and was found dead. One other domestic animal (shepherd 


\begin{tabular}{|c|c|c|c|c|c|}
\hline Post-exposure prophylaxis & $\begin{array}{l}\text { Exposure } \\
\text { category la }\end{array}$ & $\begin{array}{l}\text { Exposure } \\
\text { category II }\end{array}$ & $\begin{array}{l}\text { Exposure } \\
\text { category IIIa }\end{array}$ & $\begin{array}{c}\text { Exposure } \\
\text { undetermined }\end{array}$ & Total \\
\hline Vaccine only & 1 & 14 & 36 & 5 & 56 \\
\hline Vaccine and anti-rabies immunoglobin & 0 & 7 & 39 & 2 & 48 \\
\hline Total (\%) & $1(1)$ & $21(20)$ & $75(72)$ & $7(7)$ & $104(100)$ \\
\hline
\end{tabular}

a Exposure categories according to WHO criteria [2]. Category I: touching animals, licks on intact skin; Category II: nibbling of uncovered skin, minor scratches or abrasions without bleeding; Category III - single or multiple transdermal bites or scratches, contamination of mucous membrane with saliva from licks, licks on broken skin, exposures to bats.

b Undetermined category of exposure refers to cases with insufficient information.

dog) suspected of infection due to aggressive behavior was destroyed and found positive for rabies.

In total 104 human exposures (category I: 1; 1\%; category II: $21 ; 20$; category III: $75 ; 72 \%$ and $7 ; 7 \%$ unknown) have been reported to KEELPNO resulting in the administration of post-exposure prophylaxis according to the WHO criteria [2] (Table). All but 14 (six for each domestic rabid dog and two for the rabid cat) were exposures to potentially rabid animals and occurred in areas/prefectures within $50 \mathrm{~km}$ radius of a confirmed rabies case in a wild or domestic animal. Sixty-six per cent (68 of 104) of the exposures were reported in males and the mean age of the exposed persons was 34 years (range 6-83 years).

In most instances (95 of 104; 91\%) dogs were the animals involved. In 82 incidents dogs were involved, in five incidents cats, in one a weasel and in one the animal was not identified by the exposed individual. In the dog incidents, stray dogs represented the majority $(n=63 ; 77 \%)$ followed by domestic dogs $(n=15 ; 18 \%)$ and shepherd dogs $(n=4 ; 5 \%)$. In each incident a mean of 1.2 persons were exposed (range 1-6 individuals).

\section{Rabies situation in the Balkans countries}

Although Greece was declared rabies-free in 1987, reports of rabies in wild and domestic animals exist for the neighboring countries [3-7]. In fact rabies appears to be prevalent in a number of reservoir species in southeastern Europe and in countries north and east of Greece [6]. Recent phylogenetic analyses have shown a westward movement of rabies via the movement of wild animals from Bulgaria to other Balkan countries suggesting that this is a local event unrelated to the circulation of phylogenetically distinct viral strains in Turkey [6]. In addition, in a previous study a distinct group of viruses identified in foxes in Serbia provided evidence for southward movement of rabies from Hungary, Serbia and Romania into Bulgaria [4]. In another report that compared the nucleoprotein sequence among animal rabies isolates from three Balkan countries, including recent isolates from the years 2011-12, all strains belonged to the eastern European group implicating wildlife movement in the transmission of rabies across the region [7]. However, more information is necessary regarding the circulation of the virus and more genotypic data will assist in establishing a pattern for the spread of disease. Only one autochthonous human rabies case was reported in 2009 in the European Union, in Romania,a person bitten by a fox [8].

\section{Public health measures in Greece}

Following the report of the first domestic animal case of rabies in the area of Macedonia, northern Greece, several measures were undertaken by the Greek National Authorities (Ministry of Rural Development and Food and Ministry of Health).

\section{Discussion}

The reported cases of confirmed and possible human rabies exposure after domestic or stray animal contact raise important public health concerns: first, there is an urgent need for a prevalence estimate of the virus circulation in wild animals in the area of northern Greece. Such information will help guide immediate vaccination efforts targeting wild animals that are reservoirs for the virus. It is likely that the virus circulates largely in populations of red foxes as red foxes are considered as the most important wild animal reservoir [2]. Second, there is an urgent need for an immunisation program for wild animals. Experience from other countries has shown that rabies elimination cannot solely rely on measures that include farm animals or domestic pets such as compulsory vaccination and/or the control of stray animal population [9]. Reducing population density through culling or sterilisation of the main wildlife reservoirs such as foxes has been the most important factor in rabies elimination in these countries [9]. Successive oral vaccination campaigns (supported by the European Community) using bait vaccines have 
Measures taken by the Greek national authorities to prevent and control the re-emergence of rabies, April 2013

Rabies alert issued to local veterinary and public health authorities, the forestry services and hunting associations.

Enhancement of existing rabies animal surveillance program and inclusion of the entire country.

High priority given to rabies immunisation of all stray cats and dogs in the affected prefectures ${ }^{\text {a }}$ together with strict enforcement of the national law on compulsory rabies vaccination for pet animals.

Publication on the KEELPNO website (www.keelpno.gr) of educational material on rabies as well as information regarding pre- and post- exposure prophylaxis i.e guidance for healthcare workers on the response to human cases with potential exposure.

Creation of a network of reference hospitals for each of the seven administrative health districts of the country to respond to a potential human case along with setting up a stockpile of human rabies immuneglobulin and vaccine.

Creation of an inter-sectoral group at the Ministry of Health, consisting of epidemiologists, veterinarians, infectious disease and other public health professionals to provide continuous evaluation of the situation, scientific advice and risk assessment.

Prioritisation of preventive vaccination for specific high risk groups e.g. game wardens and veterinarians participating in the rabies surveillance program in animals.

Prefectures with confirmed rabies in animals in October 2012 to end March 2013: Kozani, Kastoria, Kilkis, Pella, Trikala. not permitted. Other strategies pertaining to hunting animals such as the prohibition of hunting with dogs have not been discussed yet; nevertheless, the obligation to keep dogs on a leash is recommended. Fourth, the public needs to be aware about the potential for rabies exposures in areas where the virus circulates in wild animals. Pre-exposure vaccination for high risk groups is a priority in our targeted initial interventions. The travel health department of KEELPNO is advising for preventive measures e.g. avoiding contact with wild and domestic animals, special attention for children exposure and pre-exposure prophylaxis only for high risk groups (e.g. game wardens, hunters, veterinarians working in the field) travelling to the affected areas; it also encourages the use of post-exposure prophylaxis according to the WHO guidelines. Currently, the risk of rabies to travelers to Greece remains extremely low and so far only the northern part of the country is affected. Fifth, healthcare workers need to carefully evaluate each human exposure from a potentially rabied animal and take the appropriate actions. Since the human rabies immunoglobulin is expensive, a risk assessment as proposed by WHO [2] should guide a cost-effective approach in its administration.

Last but not least and since the disease was likely introduced to Greece by rabid wild foxes crossing borders in the north of the country, close collaboration with the neighboring countries is of paramount importance especially with regards to control measures in wild animals.

Rabies remains an infectious disease with almost $100 \%$ fatality. The reappearance of rabies in Greece highlights the importance of rabies control measures not only in our country and its neighbors but throughout Europe. Italy recently reported the re-appearance of rabies in wild animals and implemented an extensive array of measures [11-13]. The institution of appropriate measures through a cross-sectoral collaboration between veterinary and human health authorities, together with an educational campaign for the public, the veterinary community as well as healthcare workers, will be crucial and potentially effective in preventing the re-emergence of human cases in Greece and other European countries. been successful in this regard in recent elimination efforts in some European countries for example Estonia but not in others e.g. Latvia and Lithuania [9]. Third, all domestic and stray animals especially in areas where sylvatic rabies is prevalent should be vaccinated; since the majority of the bites originated from stray dogs they should be targeted first. Unofficial information about illegal importation of unimmunised hunting dogs justify the implementation of strict border control, hygiene and immunisation checks and appropriate quarantine during the importation process of such animals according to relevant EU legislation [10]. In Greece, all imported dogs are checked for rabies immunisation with appropriate documentation together with antibody titers and if negative, entry to the country is 


\section{Acknowledgements}

Members of the rabies study and response group are acknowledged for their contribution.

Hellenic Center for Disease Control and Prevention, Ministry of Health, Athens, Greece: Nikoletta Mavroidi, Ioanna Magaziotou. National Health Operations Center of the Ministry of Health (EKEPY), Athens, Greece: Aikaterini Karageorgou. Veterinary Department, Kastoria Office, Western Macedonia Prefecture, Greece: Iordanis Antoniadis. Department of Public Health, Kastoria Office, Western Macedonia Prefecture, Greece: Artemis Komianou. Department of Surgery, Kastoria Hospital: Panagiotis Papadiamantopoulos. Department of Animal Production, Technological Institute (TEI) of Larissa, Larissa, Greece: Vassiliki Spyrou. Special Secreteriat for forests: Nikolaos Bokaris. University of Athens Medical School: George Daikos.

\section{Authors' contributions}

Sotirios Tsiodras and Georgios Dougas prepared the first draft of this manuscript. Georgios Dougas, Agoritsa Baka, Theano Georgakopoulou, Asimina Balaska, Georgios Rigakos, Dimitrios Iliopoulos and Spyros Sapounas provided the surveillance and human exposure and prophylaxis data. Spyros Doudounakis, Charalambos Billinis, Vassileios Kontos, Konstantia E. Tasioudi, Myrsini Tzani, Paraskevi Tsarouxa, Peristera Iliadou and Olga Mangana-Vougiouka were part of the response team in the veterinary section and provided the animal rabies data. Spyros Doudounakis was responsible for the animal virological data. All authors were members of national or local committees taking the several measures regarding rabies response and reported data on taken measures and actions. All authors read and critically revised the first as well as the subsequent and final drafts of this manuscript.

\section{Conflict of interest}

None declared.

\section{* Authors' correction:}

In the original publication, the list of authors and the authors' contributions was incomplete. This mistake was corrected on request of the authors on 17 May 2013.

\section{References}

1. Seimenis A, Mangana O, Nomicou V. Epidemiology and diagnosis of rabies in Greece. Parassitologia. 1988;30(1):93-5. PMid:3077442

2. Rabies vaccines: WHO position paper--recommendations. Vaccine. 2010;28(44):7140-2. http://dx.doi.org/10.1016/j. vaccine.2010.08.082 PMid:20831913

3. Johnson N, Un H, Fooks AR, Freuling C, Muller T, Aylan O, et al. Rabies epidemiology and control in Turkey: past and present. Epidemiol Infect. 2010;138(3):305-12. http://dx.doi. org/10.1017/So950268809990963 PMid:19814851

4. McElhinney LM, Marston DA, Freuling CM, Cragg W, Stankov S, Lalosevic D, et al. Molecular diversity and evolutionary history of rabies virus strains circulating in the Balkans. J Gen Virol. 2011;92(Pt 9):2171-80. http://dx.doi.org/10.1099/vir.0.032748o PMid:21632560

5. Djuricic B, Vukelic O, Knezevic N, Radojicic S, Ungurovic U, Debeljak Z, et al. Epizootiological characteristics of rabies in Serbia and Montenegro, 1993-2004. Dev Biol (Basel). 2006;125:51-8.

6. Johnson N, Fooks AR, Valtchovski R, Muller T. Evidence for trans-border movement of rabies by wildlife reservoirs between countries in the Balkan Peninsular. Vet Microbiol. 2007;120(1-2):71-6. http://dx.doi.org/10.1016/j. vetmic.2006.10.012 PMid:17129686

7. Picard-Meyer E, Mrenoshki S, Milicevic V, Ilieva D, Cvetkovikj I, Cvetkovikj A, et al. Molecular characterisation of rabies virus strains in the Republic of Macedonia. Arch Virol. 2013;158(1):237-40. http://dx.doi.org/10.1007/s00705-0121466-9 PMid:23001721

8. European Centre for Disease Prevention and Control (ECDC). Annual epidemiological report. Reporting on 2009 surveillance data and 2010 epidemic intelligence data. Stockholm:ECDC;2011. Available from: http://ecdc.europa. eu/en/publications/Publications/1111_SUR_Annual_ Epidemiological_Report_on_Communicable__Diseases_in_ Europe.pdf\#page $=185$.

9. Cliquet F, Robardet E, Must K, Laine M, Peik K, Picard-Meyer E, et al. Eliminating rabies in Estonia. PLoS Negl Trop Dis. 2012;6(2):e1535.

10. European Commission. Regulation (EC) No $998 / 2003$ of the European Parliament and of the Council of 26 May 2003 on the animal health requirements applicable to the noncommercial movement of pet animals and amending Council Directive 92/65/EEC. Official Journal of the European Union. Luxembourg: Publications Office of the European Union. 13 Jun 2005: L 146. Available from: http://ec.europa.eu/food/animal/ liveanimals/pets/reg 998 2003 en.pdf.

11. Mulatti P, Ferre N, Patregnani T, Bonfanti L, Marangon S Geographical information systems in the management of the 2009-2010 emergency oral anti-rabies vaccination of foxes in north-eastern Italy. Geospat Health. 2011;5(2):217-26. PMid:21590672

12. Mulatti P, Muller T, Bonfanti L, Marangon S. Emergency oral rabies vaccination of foxes in Italy in 2009-2010: identification of residual rabies foci at higher altitudes in the Alps. Epidemiol Infect. 2011;140(4):591-8. http://dx.doi.org/10.1017/ So950268811001282 PMid:21740611

13. European Centre for Disease Prevention and Control (ECDC). No author listed. Rabies in Northern Italy. Stockholm:ECDC;2010. Available from: http://ecdc.europa.eu/en/activities/sciadvice/ Lists/ECDC\%20Reviews/ECDC DispForm.aspx?List $=512 \mathrm{ff} 74 \mathrm{f}-$ $77 \mathrm{~d} 4-4 \mathrm{ad} 8$-b6d6-bfof 23083 f $30 \&$ ID $=778$ \& RootFolder $=\% 2$ Fen $\%$ 2Factivities\%2Fsciadvice\%2FLists\%2FECDC\%2oReviews. 